\title{
Xerostomia, Salivary Flow, and Oral Health Status Among Saudi Diabetic Patients: A Comparative Cross-Sectional Study
}

\author{
Sadeq A Al-Maweri (D) \\ Manar Omar Altayyar ${ }^{2}$ \\ Khalil Wassam AIQahtani ${ }^{3}$ \\ Maryam Saleh Bamasud ${ }^{4}$ \\ Ohud Yanalah AIGhamdi ${ }^{5}$ \\ Sajna Ashraf iD ${ }^{6}$ \\ Rawah Eshky ${ }^{7}$ \\ Raidan Ba-Hattab' \\ Saba Kassim (iD) ${ }^{8}$ \\ 'College of Dental Medicine, QU Health, \\ Qatar University, Doha, Qatar; \\ ${ }^{2}$ Department of Dentistry, Nebras \\ Medical Center, Riyadh, Saudi Arabia; \\ ${ }^{3}$ Department of Endodontics, King Saud \\ Medical City, Riyadh, Saudi Arabia; \\ ${ }^{4}$ Department of Dentistry, Saudi Ministry \\ of Health, Sakaka city, Jouf Region, Saudi \\ Arabia; ${ }^{5}$ Department of Dentistry, Saudi \\ Ministry of Health, Khobar, Eastern \\ Province, Saudi Arabia; ${ }^{6}$ Department of \\ Oral Medicine and Diagnostic Sciences, \\ Vision Colleges, Riyadh, Saudi Arabia; \\ ${ }^{7}$ Department of Orthodontics and \\ Pediatric Dentistry, College of Dentistry, \\ Taibah University, Al-Madinah Al- \\ Munawwarah, Saudi Arabia; ${ }^{8}$ Department \\ of Preventive Dental Sciences, College of \\ Dentistry, Taibah University, Al-Madinah \\ Al-Munawwarah, Saudi Arabia
}

Correspondence: Sadeq A AI-Maweri College of Dental Medicine, QU Health, Qatar University, Doha, Qatar

Tel +97433838572

Email sadali05@hotmail.com
Purpose: Diabetes mellitus (DM) is associated with numerous oral complications, including frequent oral infections, periodontal diseases, hyposalivation, and xerostomia. The present study aimed to investigate salivary flow rate, xerostomia, and oral health status among a group of Saudi diabetic patients as compared to healthy controls.

Patients and Methods: This comparative cross-sectional study involved 50 diabetic patients (aged between 15 and 70 years) and 53 age- and gender-matched healthy controls. Data collection was carried out using a structured questionnaire and clinical examination of oral health status, which included salivary flow rates, saliva $\mathrm{pH}$, tooth loss, plaque accumulation, and gingival health. Independent $t$-tests, one-way analysis of variance (ANOVA), and chi-square tests were performed to compare between groups.

Results: The results revealed a statistically significant lower salivary flow $(0.33 \pm 0.16$ vs $0.59 \pm$ $0.54 ; \mathrm{p}=0.002)$ and lower saliva $\mathrm{pH}(6.36 \pm 0.49$ vs $6.58 \pm 0.39 ; \mathrm{p}=0.014)$ in diabetic patients than in the control group. A higher proportion of diabetic subjects $(60 \%)$ self-reported having xerostomia compared to controls $(52 \%)$, but the findings were statistically non-significant. Additionally, the results revealed slightly poorer oral health and greater tooth loss among DM patients, although the results did not attain a significant difference $(\mathrm{P}>0.05)$.

Conclusion: The findings of the present study demonstrate poor oral health and a high prevalence of xerostomia among Saudi diabetic patients. Oral health education should therefore be promoted in this group of patients.

Keywords: oral health, salivary flow rate, xerostomia, diabetes mellitus

\section{Introduction}

Diabetes mellitus (DM) is a group of metabolic disorders characterized by a sustained high level of glucose in the blood (hyperglycemia) due to insulin deficits, either in function or production. ${ }^{1}$ The American Diabetes Association divided DM into four categories: type 1 diabetes, type II diabetes, gestational DM, and specific types of diabetes related to other causes. Type 1 diabetes mellitus (T1DM) accounts for 5-10\% of diabetes cases, and type 2 DM (T2DM) is the most common and accounts for 90$95 \%$ of all cases. ${ }^{2} \mathrm{DM}$ is a serious disease that has a major impact on the lives and wellbeing of individuals, with grave health and economic consequences worldwide. $^{1,3,4}$ The global prevalence of DM was estimated at 9.3\% (463 million cases) in 2019; ${ }^{4,5}$ and according to the International Diabetes Federation (IDF), the number of diabetes cases increased from 285 million in 2009 to 382 million in 2013 and 463 million in 2019. 5 
Diabetes is associated with serious systemic complications, including cardiovascular disorders, retinopathy, nephropathy, neuropathy, and many others. ${ }^{6-9}$ In addition, DM is associated with a multitude of oral and dental complications, including severe periodontitis, premature tooth loss, hyposalivation (an objective decrease in the volume of saliva), xerostomia (subjective complaint of dry mouth), taste alteration, oral candidiasis, and bacterial/viral infections. ${ }^{10-}$ ${ }^{15}$ Notably, hyposalivation is a very common devastating complication of DM. ${ }^{16}$ Hyposalivation gravely affects the quality of life, and is associated with various oral diseases such as dental caries, periodontitis (leading to tooth loss), and a myriad of oral infections. ${ }^{17,18}$ Additionally, hyposalivation can cause difficulty in eating, speaking, and swallowing, which further impairs patients' quality of life. ${ }^{17,19}$

A number of studies worldwide have documented dental and oral changes among diabetic populations. ${ }^{10,11,15,16,20,21}$ The results revealed poorer oral health and a higher prevalence of hyposalivation, xerostomia, and oral mucosal lesions among diabetic patients compared to healthy controls. In addition, a number of studies have revealed a significant association between poor glycemic control and the occurrence of oral complications. ${ }^{10,15}$ In the Kingdom of Saudi Arabia (KSA), DM is a major public health concern with a significant increase in prevalence rates over the past two decades: $:^{22-24}$ the prevalence rate increased from $13.6 \%$ in 2013 to $19.0 \%$ in 2017 , and the figure is still on the rise. ${ }^{22,25}$ Despite the high prevalence of DM in Saudi Arabia, research on the impact of DM on oral health is scarce. Documenting the oral health status of diabetic patients is very important for public health planning and the wellbeing of diabetic patients. Therefore, the present study aimed to: 1) assess the oral health status, xerostomia, and salivary flow among patients with DM in Saudi Arabia as compared to healthy controls, and 2) assess the potential association between salivary flow rate and diabetes-related variables such as type of diabetes, duration of diabetes, and glycemic control level.

\section{Patients and Methods}

\section{Study Design, Setting, Sampling, and Ethical Considerations}

This comparative, cross-sectional study was conducted on a convenience sample of 50 diabetic patients and 53 age- and gender-matched non-diabetic controls. The study was conducted in King Fahad Medical City, Riyadh, KSA, between July and December 2019. The study was approved by the
Institutionalized Review Board of King Fahad Medical City (Ref No: 19-290E) and was conducted in full compliance with the ethical principles of the World Medical Association Declaration of Helsinki. All participants were informed of the objectives of the study, and anonymity, confidentiality of responses, and voluntarism of participation were emphasized and written consent was obtained. The study adhered to the STROBE statements for observational studies. ${ }^{26}$

The required sample size was estimated based on the prevalence of xerostomia and salivary flow rate in diabetic patients reported in a previous study. ${ }^{27}$ Considering a precision of 0.05 with a $95 \%$ confidence interval and a $Z$ score of 1.96, the estimated sample size was 90 patients ( 45 in the diabetes group and 45 in control group). In order to compensate for any potential dropout, $10 \%$ was added, making a total of 50 patients in each group.

The inclusion criteria of the study were: Saudi citizens; type 1 or 2 DM patients; $\geq 15$ years old; duration of diabetes $\geq 1$ year; and availability of medical records. The exclusion criteria were: tobacco use; alcohol consumption; pregnant and breastfeeding women; history of head and neck radiotherapy/chemotherapy; hospitalized patients; patients who had received professional periodontal treatment during the last six months; patients with Sjögren syndrome or any other systemic diseases known to induce xerostomia, such as rheumatoid arthritis, polyarteritis nodosa, systemic sclerosis, or lupus erythematosus; and patients under medication that may cause dry mouth, such as antihistamines, anticholinergics, antihypertensives, and tricyclic antidepressants. Diabetic subjects were recruited from the department of endocrinology, while controls with self-reported clinically fasting blood glucose levels of less than $110 \mathrm{mg} / \mathrm{dl}$ were recruited from the outpatient clinics at King Fahad Medical City, Riyadh, KSA.

\section{Data Collection}

\section{Demographic and Clinical Data}

A structured interview questionnaire was used to collect demographic data on the subjects (age, gender, education level, marital status, medical history, medications in use). Medical history and diabetes-related variables, such as type and duration of diabetes, diabetes therapy, and HBAc1 for the past six months were collected from the medical records. Diabetic patients were categorized into three groups based on their glycemic control: 1) good metabolic control, $\mathrm{HbA} 1 \mathrm{c} \leq 6.5 \%$; 2) moderate metabolic control, HbAlc 6.6-> 8.9\%; and 3) poorly controlled, $\mathrm{HbAlc} \geq 9 \%{ }^{15}$ 


\section{Salivary Flow and Xerostomia Assessment}

An unstimulated salivary flow rate (resting saliva) was used to assess hyposalivation. Saliva was collected by the spitting method between 8:00 a.m. and 12:00 p.m. ${ }^{27}$ The subjects were requested to fast for an hour after breakfast and were then instructed to wash their mouths before giving the sample. They were monitored and educated to keep their tongue and oral musculature as still as possible to avoid any stimulation of salivary production for five minutes. The subjects were then asked to swallow the saliva that was collected in the mouth during the rest time. After that, for the next five minutes, they were instructed not to swallow the saliva but instead to spit it into the collection cup provided. ${ }^{27}$ Salivary $\mathrm{PH}$ was assessed using a PH indicator strip.

Xerostomia was evaluated by asking the patients four questions: i) Does the amount of saliva in your mouth seem to be too little, too much, or you do not notice it? ii) Do you have any difficulty swallowing? iii) Does your mouth feel dry while eating a meal? iv) Do you sip liquids to aid in swallowing dry food? A positive response to any of the aforementioned questions indicated xerostomia. ${ }^{28}$

\section{Oral Health Status}

Clinical examination to ascertain oral health status was performed by two trained and calibrated examiners using an artificial light, mouth mirror, and periodontal probe. Oral health status was evaluated by documenting the number of teeth lost, gingival health condition, and oral hygiene status. Number of teeth lost was determined by counting the missing teeth excluding third molars. The mouth was divided into sextants, and six index teeth were utilized to ascertain oral hygiene and gingival health status. The gingival health status was evaluated using the gingival index (GI) of Loe and Silness, ${ }^{29}$ and the plaque index (PI) of Silness and Loe ${ }^{30}$ was used to ascertain oral hygiene status.

\section{Calibration of the Examiners}

Prior to the study, the two examiners were trained and calibrated by examining eight patients at "Vision Colleges Polyclinics" under the supervision of a consultant in periodontics. The Inter-examiner reliability for quantitative variables (GI and PI) was calculated using intra-class coefficient correlation. The training sessions were repeated until acceptable inter-examiner agreements were reached. The inter-examiner agreements were 0.75 and 0.80 for PI and GI, respectively.

\section{Statistical Analyses}

The collected data were analyzed using SPSS statistics software for Windows, Version 22.00 (IBM). Descriptive statistics were calculated for both groups. Normality of the quantitative data was assessed using KolmogorovSmirnov test. The chi-square test was used to analyze qualitative data, while $t$-tests or ANOVA were used to analyze quantitative data. A p-value $<0.05$ was considered statistically significant.

\section{Results}

The sociodemographic data of the subjects are presented in Table 1. A total of 50 diabetic patients (aged 15-70 years) and 53 age- and gender-matched control subjects participated in this study. The mean ages of the diabetic patients and control subjects were comparable: $41.24 \pm 18.72$ and $38.85 \pm 15.74$, respectively. Around two thirds of the subjects in both groups were females. As can be seen in Table 1, there were no significant differences between the two groups with respect to level of education, frequency of tooth brushing, medication use, and denture use $(\mathrm{P}>0.05)$. Only a small percentage of diabetic subjects and controls reported receiving any medication other than antidiabetic medications (Table 1).

Table 2 presents the diabetes-related variables among diabetic subjects. More than half of the subjects $(54 \%, \mathrm{n}=$ 27) had type 2 diabetes. The mean duration of diabetes was $12.84 \pm 6.23$ years (range: 1-27 years), with the majority of subjects (70\%) having diabetes for more than 10 years. Around $54 \%$ were on insulin, $30 \%$ on oral hypoglycemic agents, and $16 \%$ on a combination of insulin and oral hypoglycemic agents. The mean HBAc1 was $8.71 \pm 2.40$ (range: $5.2-19.9$ ), with only $16 \%$ having good metabolic control $(\mathrm{HBAC} 1 \leq 6.5)$, while the remainder were either moderately controlled $(48 \%)$ or poorly controlled (36\%) (Table 2).

Xerostomia, salivary flow, and oral health status among diabetics and controls are presented in Table 3. Diabetic patients showed significantly lower salivary flow $(0.33 \pm$ $0.16)$ compared to control subjects $(0.59 \pm 0.54 ; \mathrm{p}=$ 0.002). Saliva $\mathrm{PH}$ was significantly lower in diabetic patients than in controls $(6.36 \pm 0.49$ vs $6.58 \pm 0.39$; $\mathrm{p}=$ 0.014). Although not statistically non-significant $(\mathrm{P}>$ $0.05)$, a higher proportion of diabetic subjects $(60 \%)$ reported having xerostomia compared to controls (52\%). The mean tooth loss was higher among diabetic patients than controls $(3.50 \pm 3.84$ vs $2.53 \pm 3.84)$, although the 
Table I Demographic Data and Characteristics of Study Groups

\begin{tabular}{|c|c|c|c|}
\hline \multirow[t]{2}{*}{ Variables } & $\begin{array}{l}\text { Diabetics } \\
(n=50)\end{array}$ & $\begin{array}{l}\text { Controls } \\
(n=53)\end{array}$ & P-value \\
\hline & n (\%) & n (\%) & \\
\hline \multicolumn{4}{|l|}{ Gender } \\
\hline a. Male & 16 (32\%) & $16(30.2 \%)$ & 0.843 \\
\hline b. Female & 34 (68\%) & 37 (69.8\%) & \\
\hline Age & $41.24 \pm 18.72$ & $38.85 \pm 15.74$ & 0.486 \\
\hline \multicolumn{4}{|l|}{ Education } \\
\hline a. no schooling & $8(16 \%)$ & $9(17 \%)$ & 0.061 \\
\hline b. high school & $24(48 \%)$ & I4 (26.4\%) & \\
\hline c. University & $18(36 \%)$ & $30(56.6 \%)$ & \\
\hline \multicolumn{4}{|l|}{ Medications* } \\
\hline a. None & $42(84 \%)$ & $43(81.1 \%)$ & 0.904 \\
\hline d. NSAID & $2(4 \%)$ & $3(5.7 \%)$ & \\
\hline f. Others & $6(12 \%)$ & 7 (I3.2\%) & \\
\hline \multicolumn{4}{|l|}{ Systemic diseases } \\
\hline IYes & $12(24 \%)$ & $15(28.3 \%)$ & 0.871 \\
\hline No & $38(76 \%)$ & 38 (7I.7\%) & \\
\hline \multicolumn{4}{|l|}{ Tooth brushing } \\
\hline Twice/thrice per day & $20(40 \%)$ & 26 (49.1\%) & 0.648 \\
\hline Once daily & 14 (28\%) & $13(24.5 \%)$ & \\
\hline Irregular & $16(32 \%)$ & 14 (26.4\%) & \\
\hline \multicolumn{4}{|l|}{ Floss use } \\
\hline Yes & $9(18 \%)$ & I4 (26.4\%) & 0.305 \\
\hline No & $4 \mid(82 \%)$ & 39 (73.6\%) & \\
\hline \multicolumn{4}{|l|}{ Denture wearing } \\
\hline Yes & $3(6 \%)$ & $4(7.5 \%)$ & 0.755 \\
\hline NO & 47 (94\%) & 49 (92.5\%) & \\
\hline
\end{tabular}

Note: *Medication other than anti-diabetic drugs.

difference was statistically non-significant $(\mathrm{P}=0.322)$. The mean scores of the plaque and gingival indexes were comparable in the two groups $(\mathrm{P}>0.05)$ (Table 3$)$.

Univariate analysis of the association between salivary flow and $\mathrm{PH}$ and independent variables is presented in
Table 2 Description of Diabetes Variables Among Diabetic Patients

\begin{tabular}{|c|c|c|}
\hline \multirow[t]{2}{*}{ Variables } & \multicolumn{2}{|c|}{ Diabetic Subjects $(n=50)$} \\
\hline & n (\%) & Mean \pm SD (Range) \\
\hline \multicolumn{3}{|l|}{ Type of DM } \\
\hline Type I & $23(46 \%)$ & \\
\hline Type 2 & 27 (54\%) & \\
\hline \multicolumn{3}{|l|}{ Duration of diabetes } \\
\hline \multicolumn{3}{|l|}{ mean } \\
\hline Duration categories & & $12.84 \pm 6.23(I-27)$ \\
\hline (a) < IOyrs & $15(30 \%)$ & \\
\hline (b) $>10 \mathrm{yrs}$ & $35(70 \%)$ & \\
\hline \multicolumn{3}{|l|}{ Treatment of DM } \\
\hline (a) Oral agents & $15(30 \%)$ & \\
\hline (b) Insulin & $27(54 \%)$ & \\
\hline (c) Insulin + Oral agents & $8(16 \%)$ & \\
\hline Metabolic control & & $8.71 \pm 2.40(5.2-19.9)$ \\
\hline \multicolumn{3}{|l|}{ (HBAcl) } \\
\hline a-(a) Good & $8(16 \%)$ & \\
\hline b-(b) Moderate & $24(48 \%)$ & \\
\hline c-(c) Poor & $18(36 \%)$ & \\
\hline
\end{tabular}

Table 4. There were no statistically significant differences between salivary flow and/or PH and various independent variables $(\mathrm{P}>0.05)$. Subjects with poor metabolic control $(\mathrm{HbAc1} \geq 9)$ had non-significantly lower salivary flow and lower PH than those with good/moderate metabolic control $(0.29 \pm 0.11$ vs $0.37 \pm 0.18, p=0.066$; and $6.26 \pm 0.39$ vs $6.41 \pm 0.54, \mathrm{p}=0.276$, respectively).

There was no significant association between reported xerostomia and independent variables, such as age, type of diabetes, metabolic control, and medication (Table 5). Meanwhile, xerostomia prevalence was markedly higher in patients with type 2 diabetes compared to those with type 1 diabetes $(70.4 \%$ vs $47.8 \%)$, in poorly controlled subjects compared to well controlled subjects $(66.7 \%$ vs

Table 3 Xerostomia, Salivary Flow, and Oral Health Variables Among Diabetics and Controls

\begin{tabular}{|l|c|c|c|}
\hline \multirow{2}{*}{ Variables } & Diabetics $\mathbf{~}=\mathbf{5 0}$ & Control $\mathbf{n}=\mathbf{5 3}$ & \multirow{2}{*}{ P-value* } \\
\cline { 2 - 4 } & $\mathbf{N}$ & $\mathbf{n}$ & 0.463 \\
\hline Xerostomia & $30(60 \%)$ & $28(52.8 \%)$ & 0.002 \\
Salivary flow & $0.33 \pm 0.16$ & $0.59 \pm 0.54$ & 0.014 \\
Saliva PH & $6.36 \pm 0.49$ & $6.58 \pm 0.39$ & 0.640 \\
GI & $1.37 \pm 0.47$ & $1.32 \pm 0.59$ & 0.512 \\
PI & $1.53 \pm 0.57$ & $1.46 \pm 0.611$ & 0.322 \\
Tooth loss & $3.50 \pm 3.84$ & $2.53 \pm 3.84$ & \\
\hline
\end{tabular}

Note: *P-value significant level at $<0.05$. 
Table 4 Salivary Flow and PH Among Diabetic Patients by Various Variables

\begin{tabular}{|c|c|c|}
\hline \multirow[t]{2}{*}{ Variable } & Salivary Flow & PH \\
\hline & Mean士SD & Mean \pm SD \\
\hline \multicolumn{3}{|l|}{ Gender } \\
\hline Male & $0.38 \pm 0.22$ & $6.44 \pm 0.49$ \\
\hline Female & $0.32 \pm 0.13$ & $6.31 \pm 0.49$ \\
\hline P-value & 0.349 & 0.405 \\
\hline \multicolumn{3}{|l|}{ Age } \\
\hline$\leq 40$ years & $0.35 \pm 0.15$ & $6.3 I \pm 0.45$ \\
\hline$>40$ years & $0.33 \pm 0.17$ & $6.39 \pm 0.54$ \\
\hline P-value & 0.740 & 0.578 \\
\hline \multicolumn{3}{|l|}{ Type diabetes } \\
\hline Type I & $0.36 \pm 0.16$ & $6.33 \pm 0.47$ \\
\hline Type 2 & $0.32 \pm 0.16$ & $6.37 \pm 0.52$ \\
\hline P-value & 0.502 & 0.790 \\
\hline \multicolumn{3}{|l|}{$\begin{array}{l}\text { Duration of } \\
\text { diabetes }\end{array}$} \\
\hline$<10$ years & $0.31 \pm 0.12$ & $6.30 \pm 0.45$ \\
\hline$\geq 10$ years & $0.34 \pm 0.18$ & $6.38 \pm 0.52$ \\
\hline$P$-value & 0.434 & 0.590 \\
\hline \multicolumn{3}{|l|}{ Hbacl } \\
\hline$<9$ & $0.37 \pm 0.18$ & $6.4 I \pm 0.54$ \\
\hline$\geq 9$ & $0.29 \pm 0.11$ & $6.26 \pm 0.39$ \\
\hline P-value & 0.066 & 0.276 \\
\hline \multicolumn{3}{|l|}{$\begin{array}{l}\text { Diabetes } \\
\text { therapy }\end{array}$} \\
\hline Oral & $0.31 \pm 0.133$ & 6.3200 \\
\hline Insulin & $0.37 \pm 0.188$ & 6.3963 \\
\hline Combined & $0.30 \pm 0.11$ & 6.2813 \\
\hline P-value & 0.409 & 0.807 \\
\hline \multicolumn{3}{|l|}{ Medications } \\
\hline Yes & $0.30 \pm 0.14$ & $6.35 \pm 0.40$ \\
\hline No & $0.35 \pm 0.17$ & $6.36 \pm 0.51$ \\
\hline P-value & 0.432 & 0.972 \\
\hline \multicolumn{3}{|l|}{$\begin{array}{l}\text { Systemic } \\
\text { diseases }\end{array}$} \\
\hline Yes & $0.30 \pm 0.13$ & $6.32 \pm 0.40$ \\
\hline No & $0.35 \pm 0.17$ & $6.37 \pm 0.520$ \\
\hline P-value & 0.340 & 0.730 \\
\hline
\end{tabular}

$56.2 \%$ ), and in subjects who were on a combination of therapy $(87.5 \%)$ compared to those who were on either insulin $(51.9 \%)$ or oral hypoglycemic agents $(60 \%)$; however, the association was non-significant (Table 5).

\section{Discussion}

To the best of our knowledge, this is the first study that has documented oral health status, salivary flow rate, and
Table 5 Xerostomia Among Diabetics by Various Variables

\begin{tabular}{|c|c|c|c|}
\hline Variable & $\mathbf{N}$ & $\%$ & P-value \\
\hline \multicolumn{4}{|l|}{ Gender } \\
\hline Male & 10 & 62.5 & \\
\hline Female & 20 & 58.8 & 0.804 \\
\hline \multicolumn{4}{|l|}{ Age } \\
\hline$\leq 40$ years & 11 & 47.8 & 0.105 \\
\hline$>40$ years & 19 & 70.4 & \\
\hline \multicolumn{4}{|l|}{$\begin{array}{l}\text { Type of } \\
\text { diabetes }\end{array}$} \\
\hline Type I & II & 47.8 & 0.105 \\
\hline Type 2 & 19 & 70.4 & \\
\hline \multicolumn{4}{|l|}{$\begin{array}{l}\text { Duration of } \\
\text { diabetes }\end{array}$} \\
\hline$<10$ years & 8 & 53.3 & 0.529 \\
\hline$\geq 10$ years & 22 & 62.9 & \\
\hline \multicolumn{4}{|l|}{ Hbacl } \\
\hline$<9$ & 18 & 56.2 & 0.470 \\
\hline$\geq 9$ & 12 & 66.7 & \\
\hline \multicolumn{4}{|l|}{ Diabetes } \\
\hline \multicolumn{4}{|l|}{ therapy } \\
\hline Oral & 9 & 60 & 0.195 \\
\hline Insulin & 14 & 51.9 & \\
\hline Combined & 7 & 87.5 & \\
\hline \multicolumn{4}{|l|}{ Medications* } \\
\hline Yes & 3 & 37.5 & 0.156 \\
\hline No & 27 & 64.3 & \\
\hline \multicolumn{4}{|l|}{$\begin{array}{l}\text { Systemic } \\
\text { diseases }\end{array}$} \\
\hline Yes & 9 & 75 & 0.224 \\
\hline No & 21 & 55.3 & \\
\hline
\end{tabular}

Note: *Medication other than anti-diabetic drugs.

xerostomia among Saudi diabetic patients. The present study revealed a statistically significant lower salivary flow and lower saliva $\mathrm{PH}$ among diabetic patients compared to the control group. Additionally, there was slightly poorer oral health (ie, more plaque accumulation and gingival inflammation) and greater tooth loss among the DM patients, although the results did not attain significant differences. In the present study, around two thirds of the subjects were females, while only $28 \%$ were males. The low representation of male subjects in our study can be attributed to the eligibility criteria that excluded smokers (mostly males), and hence only small proportion of male diabetic patients were included.

Diabetes mellitus is a metabolic disorder that negatively affects the function of different organs, including 
the salivary glands. ${ }^{7,9,31}$ Alterations in the salivary glands can result in a decrease in saliva, which leads to devastating consequences, such as increased susceptibility to dental caries and periodontal diseases. The present study revealed a significantly lower salivary flow in diabetic patients compared to healthy controls (we can consider that the mixtures of both types of diabetes inflated these differences). This finding is consistent with many previous studies. ${ }^{16,20,31-35}$

The decrease in saliva secretion in diabetic patients can be attributed to many factors, such as fatty infiltration of the salivary glands, hyperglycemia, glycosuria, hydration due to polyuria, and neuropathy of the salivary glands. $^{27,31,36}$ Although statistically non-significant, the present study demonstrated that diabetic patients with poor glycemic control had lower salivary flow rates than those with well-controlled diabetes. This finding is in agreement with previous studies that reported some association between poor glycemic control and oral diseases, including salivary flow and composition. ${ }^{31,32}$ Hyperglycemia can cause several pathological changes, resulting in salivary gland dysfunction and a reduction of salivary secretion. ${ }^{32}$

One of the most common symptoms associated with DM is xerostomia, ${ }^{27,35}$ the subjective feeling of having dry mouth. ${ }^{27}$ The prevalence of xerostomia in diabetic patients ranges from $12.5 \%$ to $76.4 \% .^{10,20,33-36}$ In the present study, $60 \%$ of diabetic subjects reported xerostomia compared to $52 \%$ of controls, a figure that is lower than that reported by Carda et $\mathrm{al}^{36}$ (76.4\%), but much higher than other studies by Sreebny et $\mathrm{al}^{34}(43 \%)$, Vasconcelos et $\mathrm{al}^{33}$ (12.5\%), and Carramolino-Cuéllar et $\mathrm{al}^{20}(27.7 \%)$. The large discrepancy in the prevalence of xerostomia across different studies could be related to variability in the population studied, age of the patients, heterogeneity in the type of DM, and different methodologies. Consistent with previous literature, ${ }^{10,37,38}$ xerostomia was more common among older subjects. Furthermore, xerostomia was more predominant in type 2 diabetics than in type 1 diabetics. Such results are not surprising and can be explained by the fact that type 2 diabetic patients are usually older than type 1 , and it is documented that xerostomia and salivary hypofunction are related to age. ${ }^{39}$

Another important finding of the present study is the unsatisfactory oral health of diabetic patients, which is in line with many previous studies..$^{12,32,40,41}$ Diabetic patients had greater tooth loss than healthy controls, confirming previous results..$^{21,42-44}$ Tooth loss is mainly caused by periodontitis, although other causes, such as trauma and dental caries, are implicated. The association between periodontitis and DM has been well established in the literature, ${ }^{12,40,41,45,46}$ and periodontitis is considered the sixth most common complication of diabetes mellitus. A plausible explanation for the potential association of DM with periodontal disease can be explained by different mechanisms: increased inflammatory response to periodontal pathogens, decreased tissue repair and regeneration, and the effect of advanced glycation end products. ${ }^{12,41,47}$ Periodontitis is a preventable condition that can be avoided through both personal oral hygiene practices, such as tooth brushing, and professional oral healthcare. ${ }^{48,49}$ Unfortunately, the present study revealed poor oral health status (evident by the high gingival inflammation and plaque accumulation) and poor oral hygiene practices, with only a small proportion of patients reporting regular toothbrushing. This emphasizes the importance of intensive oral health care among diabetes patients to maintain the integrity of the periodontium and dentition. ${ }^{49}$ It also underscores the need to customize oral health care programs for these patients to raise their awareness of oral hygiene and the impact of diabetes on oral health. ${ }^{50}$

The present study has some limitations that should be considered. The main limitation is that the study targeted a convenience sample of diabetic patients at one public health care center and might not be representative of all diabetic patients at other centers. As such, generalization of the results should be approached with caution. Additionally, the relatively small sample size further limits generalizability. Due to the small sample size, we could not perform multivariate analysis, which could have explained the predictors of hyposalivation and poor oral health among this group of patients. Although detection bias was controlled via training and calibration, the potential for observer bias (performance bias) cannot be overlooked in the present study. Finally, the use of only four items of "Fox's questionnaire" is another limitation of the present study. On the other hand, the present study has several strengths that should be acknowledged. As mentioned earlier, this is the first study to explore oral health conditions among diabetic patients in Saudi Arabia. Second, the present study adopted very strict inclusion and exclusion criteria. Third, the study employed healthy controls to validate the results.

In conclusion, the present study revealed a decrease in resting saliva, a high prevalence of xerostomia, and poor oral health among diabetic patients in Saudi Arabia. Oral 
health education should therefore be promoted in this group of patients. Further large-scale observational studies to in-depth explore oral complications and their associated factors among Saudi diabetic patients are highly recommended.

\section{Acknowledgments}

The authors would like to thank all medical staff at King Fahd Medical city for this support and help during data collection.

\section{Funding}

We did not receive any external funding.

\section{Disclosure}

All authors declare that they have no conflicts of interest for this work.

\section{References}

1. Chawla A, Chawla R, Jaggi S. Microvascular and macrovascular complications in diabetes mellitus: distinct or continuum? Indian $J$ Endocrinol Metab. 2016;20(4):546-551. doi:10.4103/22308210.183480

2. American Diabetes Association. 2. Classification and diagnosis of diabetes: standards of medical care in diabetes-2019. Diabetes Care. 2019;42(Suppl 1):S13-S28. doi:10.2337/dc19-S002

3. Almalki ZS, Albassam AA, Alnakhli MA, Alnusyan MF, Alanazi FN, Alqurashi MS. National rates of emergency department visits associated with diabetes in Saudi Arabia, 2011-2015. Ann Saudi Med. 2019;39(2):71-76. doi:10.5144/0256-4947.2019.71

4. Williams R, Karuranga S, Malanda B, et al. Global and regional estimates and projections of diabetes-related health expenditure: results from the International Diabetes Federation Diabetes Atlas, 9th edition. Diabetes Res Clin Pract. 2020;162:108072. doi:10.1016/j.diabres.2020.108072

5. Saeedi P, Petersohn I, Salpea P, et al. Global and regional diabetes prevalence estimates for 2019 and projections for 2030 and 2045: results from the International Diabetes Federation Diabetes Atlas, 9(th) edition. Diabetes Res Clin Pract. 2019;157:107843. doi:10.1016/j.diabres.2019.107843

6. Falcone M, Meier JJ, Giulia Marini M, et al. Diabetes and acute bacterial skin and skin structure infections. Diabetes Res Clin Pract 2021;174:108732. doi:10.1016/j.diabres.2021.108732

7. Gil CL, Hooker E, Larrivée B. Diabetic kidney disease, endothelial damage, and podocyte-endothelial crosstalk. Kidney Med. 2021;3 (1):105-115. doi:10.1016/j.xkme.2020.10.005

8. Snelson M, de Pasquale C, Ekinci EI, Coughlan MT. Gut microbiome, prebiotics, intestinal permeability and diabetes complications. Best Pract Res Clin Endocrinol Metab. 2021;35:101507. doi:10.1016/j.beem.2021.101507

9. Homoud B, Alhakami A, Almalki M, et al. The association of diabetes with ischemic stroke and transient ischemic attacks in a tertiary center in Saudi Arabia. Ann Saudi Med. 2020;40 (6):449-455. doi:10.5144/0256-4947.2020.449

10. Al-Maweri SA, Ismail NM, Ismail AR, Al-Ghashm A. Prevalence of oral mucosal lesions in patients with type 2 diabetes attending hospital universiti sains Malaysia. Malays J Med Sci. 2013;20(4):39-46.
11. Contaldo M, Romano A, Mascitti M, et al. Association between denture stomatitis, candida species and diabetic status. J Biol Regul Homeost Agents. 2019;33(3Suppl. 1):35-41.

12. Genco RJ, Borgnakke WS. Diabetes as a potential risk for periodontitis: association studies. Periodontol 2000. 2020;83(1):40-45. doi: $10.1111 /$ prd.12270

13. Genco RJ, Graziani F, Hasturk H. Effects of periodontal disease on glycemic control, complications, and incidence of diabetes mellitus. Periodontol 2000. 2020;83(1):59-65. doi:10.1111/prd.12271

14. Rohani B. Oral manifestations in patients with diabetes mellitus. World J Diabetes. 2019;10(9):485-489. doi:10.4239/wjd.v10.i9.485

15. Saini R, Al-Maweri SA, Saini D, Ismail NM, Ismail AR. Oral mucosal lesions in non oral habit diabetic patients and association of diabetes mellitus with oral precancerous lesions. Diabetes Res Clin Pract. 2010;89(3):320-326. doi:10.1016/j.diabres.2010.04.016

16. Lima DLF, Carneiro S, Barbosa FTS, Saintrain MVL, Moizan JAH, Doucet J. Salivary flow and xerostomia in older patients with type 2 diabetes mellitus. PLoS One. 2017;12(8):e0180891. doi:10.1371/ journal.pone. 0180891

17. Samnieng P, Ueno M, Shinada K, Zaitsu T, Wright FA, Kawaguchi Y. Association of hyposalivation with oral function, nutrition and oral health in community-dwelling elderly Thai. Community Dent Health. 2012;29(1):117-123.

18. Pedersen AML, Sørensen CE, Proctor GB, Carpenter GH, Ekström J. Salivary secretion in health and disease. J Oral Rehabil. 2018;45 (9):730-746. doi:10.1111/joor.12664

19. Botelho J, Machado V, Proença L, et al. Perceived xerostomia, stress and periodontal status impact on elderly oral health-related quality of life: findings from a cross-sectional survey. BMC Oral Health. 2020;20(1):199. doi:10.1186/s12903-020-01183-7

20. Carramolino-Cuéllar E, Lauritano D, Silvestre FJ, Carinci F, Lucchese A, Silvestre-Rangil J. Salivary flow and xerostomia in patients with type 2 diabetes. J Oral Pathol Med. 2018;47 (5):526-530. doi:10.1111/jop.12712

21. Delgado-Pérez VJ, De La Rosa-santillana R, Márquez-Corona ML, et al. Diabetes or hypertension as risk indicators for missing teeth experience: an exploratory study in a sample of Mexican adults. Niger J Clin Pract. 2017;20(10):1335-1341. doi:10.4103/njcp.njcp_52_17

22. Alsuliman MA, Alotaibi SA, Zhang Q, Durgampudi PK. A systematic review of factors associated with uncontrolled diabetes and meta-analysis of its prevalence in Saudi Arabia since 2006. Diabetes Metab Res Rev. 2020;37:e3395.

23. Alharbi TJ, Tourkmani AM, Rsheed AB, Al Abood AF, Alotaibi YK. Sociodemographic and clinical predictors of refractory type 2 diabetes patients: findings from a case-control study. Saudi Med J. 2021;42(2):181-188. doi:10.15537/smj.2021.2.25694

24. Tourkmani AM, Alharbi TJ, Bin rsheed A, Alotaibi YK. Utilizing diabetes registry for exploring sociodemographic and clinical characteristics of type II diabetic patients in Saudi Arabia. Saudi Med J. 2021;42(1):56-65. doi:10.15537/smj.2021.1.25629

25. Cho NH, Shaw JE, Karuranga S, et al. IDF Diabetes Atlas: global estimates of diabetes prevalence for 2017 and projections for 2045 . Diabetes Res Clin Pract. 2018;138:271-281. doi:10.1016/j. diabres.2018.02.023

26. von Elm E, Altman DG, Egger M, Pocock SJ, Gøtzsche PC, Vandenbroucke JP. The Strengthening the Reporting of Observational Studies in Epidemiology (STROBE) statement: guidelines for reporting observational studies. J Clin Epidemiol. 2008;61 (4):344-349. doi:10.1016/j.jclinepi.2007.11.008

27. Malicka B, Kaczmarek U, Skośkiewicz-Malinowska K. Prevalence of xerostomia and the salivary flow rate in diabetic patients. $A d v$ Clin Exp Med. 2014;23(2):225-233. doi:10.17219/acem/37067

28. Fox PC, van der Ven PF, Sonies BC, Weiffenbach JM, Baum BJ. Xerostomia: evaluation of a symptom with increasing significance. $J$ Am Dent Assoc. 1985;110(4):519-525. doi:10.14219/jada. archive. 1985.0384 
29. Loe H, Silness J. PERIODONTAL DISEASE IN PREGNANCY. I. PREVALENCE AND SEVERITY. Acta Odontol Scand. 1963;21:533-551. doi:10.3109/00016356309011240

30. Silness J, Loe H. PERIODONTAL DISEASE IN PREGNANCY. II. CORRELATION BETWEEN ORAL HYGIENE AND PERIODONTAL CONDTION. Acta Odontol Scand. 1964;22:121-135. doi: $10.3109 / 00016356408993968$

31. Rahiotis C, Petraki V, Mitrou P. Changes in saliva characteristics and carious status related to metabolic control in patients with type 2 diabetes mellitus. $J$ Dent. 2021;108:103629. doi:10.1016/j. jdent.2021.103629

32. Díaz Rosas CY, Cárdenas Vargas E, Castañeda-Delgado JE, AguileraGalaviz LA, Aceves Medina MC. Dental, periodontal and salivary conditions in diabetic children associated with metabolic control variables and nutritional plan adherence. Eur $J$ Paediatr Dent. 2018;19(2):119-126.

33. Vasconcelos AC, Soares MS, Almeida PC, Soares TC. Comparative study of the concentration of salivary and blood glucose in type 2 diabetic patients. J Oral Sci. 2010;52(2):293-298. doi:10.2334/ josnusd.52.293

34. Sreebny LM, Yu A, Green A, Valdini A. Xerostomia in diabetes mellitus. Diabetes Care. 1992;15(7):900-904. doi:10.2337/ diacare.15.7.900

35. López-Pintor RM, Casañas E, González-Serrano J, et al. Xerostomia, hyposalivation, and salivary flow in diabetes patients. $J$ Diabetes Res. 2016;2016:4372852. doi:10.1155/2016/4372852

36. Carda C, Mosquera-Lloreda N, Salom L, Gomez de Ferraris ME, Peydró A. Structural and functional salivary disorders in type 2 diabetic patients. Med Oral Patol Oral Cir Bucal. 2006;11(4):E309-314.

37. Villa A, Polimeni A, Strohmenger L, Cicciù D, Gherlone E, Abati S. Dental patients' self-reports of xerostomia and associated risk factors. $J \quad$ Am Dent Assoc. 2011;142(7):811-816. doi:10.14219/jada. archive.2011.0269

38. Liu B, Dion MR, Jurasic MM, Gibson G, Jones JA. Xerostomia and salivary hypofunction in vulnerable elders: prevalence and etiology. Oral Surg Oral Med Oral Pathol Oral Radiol. 2012;114(1):52-60. doi:10.1016/j.oooo.2011.11.014

39. Al-Maweri SA, Al-Jamaei AA, Al-Sufyani GA, Tarakji B, ShugaaAddin B. Oral mucosal lesions in elderly dental patients in Sana'a, Yemen. J Int Soc Prev Commun Dent. 2015;5(Suppl 1):S12-19. doi:10.4103/2231-0762.156152
40. Kaur G, Holtfreter B, Rathmann W, et al. Association between type 1 and type 2 diabetes with periodontal disease and tooth loss. J Clin Periodontol. 2009;36(9):765-774. doi:10.1111/j.1600-051X.2009.01445.X

41. Khalifa N, Rahman B, Gaintantzopoulou MD, Al-Amad S, Awad MM. Oral health status and oral health-related quality of life among patients with type 2 diabetes mellitus in the United Arab Emirates: a matched case-control study. Health Qual Life Outcomes. 2020;18(1):182. doi:10.1186/s12955-020-01418-9

42. Rodrigues C, Anjaly D, Rashmi B. Diabetes and tooth loss. $J$ Evol Med Dent Sci. 2013;2(25):4516-4523. doi:10.14260/jemds/871

43. López-Gómez SA, González-López BS, Scougall-Vilchis RJ, et al. Tooth loss in patients with and without diabetes: a large-scale, cross-sectional study of Mexican adults. $J$ Am Dent Assoc. 2020;151(4):276-286. doi:10.1016/j.adaj.2019.12.015

44. Kawahara H, Inoue M, Okura K, Oshima M, Matsuka Y. Risk factors for tooth loss in patients undergoing mid-long-term maintenance: a retrospective study. Int $J$ Environ Res Public Health. 2020;17 (17):6258. doi:10.3390/ijerph17176258

45. Lavigne SE, Forrest JL. An umbrella review of systematic reviews examining the relationship between type 2 diabetes and periodontitis: position paper from the Canadian Dental Hygienists Association. Can $J$ Dent Hyg. 2021;55(1):57-67.

46. Demmer RT, Holtfreter B, Desvarieux M, et al. The influence of type 1 and type 2 diabetes on periodontal disease progression: prospective results from the Study of Health in Pomerania (SHIP). Diabetes Care. 2012;35(10):2036-2042. doi:10.2337/dc11-2453

47. Chapple IL, Genco R. Diabetes and periodontal diseases: consensus report of the Joint EFP/AAP workshop on periodontitis and systemic diseases. J Periodontol. 2013;84(4 Suppl):S106-112. doi:10.1902/ jop.2013.1340011

48. Al-Maweri SA, Nassani MZ, Alaizari N, et al. Efficacy of aloe vera mouthwash versus chlorhexidine on plaque and gingivitis: a systematic review. Int $J$ Dent Hyg. 2020;18(1):44-51. doi:10.1111/idh.12393

49. Valentim FB, Carneiro VC, Costa Gomes PD, Rosetti EP. The importance of integrated healthcare in the association between oral health and awareness of periodontitis and diabetes in type 2 diabetics. Oral Health Prev Dent. 2021;19(1):1-6.

50. Almehmadi AH, Alzaid G, Quqandi S, et al. Awareness of the effect of diabetes on oral health among a population in Jeddah, Saudi Arabia. Oral Health Prev Dent. 2020;18(1):27-34.
Clinical, Cosmetic and Investigational Dentistry

\section{Publish your work in this journal}

Clinical, Cosmetic and Investigational Dentistry is an international, peer-reviewed, open access, online journal focusing on the latest clinical and experimental research in dentistry with specific emphasis on cosmetic interventions. Innovative developments in dental materials, techniques and devices that improve outcomes and patient satisfaction and preference will be highlighted. The manuscript management system is completely online and includes a very quick and fair peer-review system, which is all easy to use. Visit http://www.dovepress.com/testimonials.php to read real quotes from published authors. 